\title{
Fronteras culturales difusas: autonomía étnica e identidad en textos andinos del siglo XVII
}

Frontières culturelles diffuses : l'autonomie ethnique et l'identité dans les textes andins du XVIIè siècle

Diffuse cultural frontiers: ethnic autonomy and identity in andean texts of the XVIIth century

\section{Alcira Dueñas}

\section{OpenEdition}

Journals

\section{Edición electrónica}

URL: http://journals.openedition.org/bifea/3404

DOI: 10.4000/bifea.3404

ISSN: 2076-5827

Editor

Institut Français d'Études Andines

Edición impresa

Fecha de publicación: 1 abril 2008

Paginación: 187-197

ISSN: 0303-7495

Referencia electrónica

Alcira Dueñas, «Fronteras culturales difusas: autonomía étnica e identidad en textos andinos del siglo XVII », Bulletin de I'Institut français d'études andines [En línea], 37 (1) | 2008, Publicado el 01 octubre 2008, consultado el 27 noviembre 2020. URL : http://journals.openedition.org/bifea/3404 ; DOI : https://doi.org/10.4000/bifea.3404

\section{BY NE ND}

Les contenus du Bulletin de l'Institut français d'études andines sont mis à disposition selon les termes de la licence Creative Commons Attribution - Pas d'Utilisation Commerciale - Pas de Modification 4.0 International. 
TerCera PARTE

LA COLONIA NEGOCIADA 



\title{
Fronteras culturales difusas: autonomía étnica e identidad en textos andinos del siglo XVII
}

\author{
Alcira Dueñas*
}

\section{Resumen}

Este ensayo examina algunas nociones de poder étnico y construcciones discursivas de identidad que figuran prominentemente en dos complejos textos andinos del siglo XVII, posteriores a las obras de Guaman Poma de Ayala y Garcilaso de la Vega. Replanteando principios medievales escolásticos como «derecho natural», «bien común» y «buen gobierno», estos escritos buscaron legitimar el derecho de los sujetos andinos al gobierno de sus cacicazgos, dado que el dominio español en el Perú transgredió tales principios básicos de legitimidad. Cuestionando los abusos y el racismo a que estuvieron sometidos los indígenas, los manuscritos ponen de relieve las contradicciones inherentes al colonialismo, particularmente el efecto perturbador de las reformas toledanas que desataron la esclavitud indígena y el declinar de los cacicazgos andinos. Identificándose como «noble», «cristiano», y «sujeto leal», el autor andino intentaba una negociación cultural con la Corona para la obtención del cacicazgo y la apertura de espacios de autoridad étnica y prestigio social, a la vez que adelantaba un cuestionamiento de las jerarquías raciales del colonialismo español.

Palabras clave: autogobierno andino, escritura andina, inclusión social andina, identidad étnica, racismo colonial

\section{Frontières culturelles diffuses : l'autonomie ethnique et l'identité dans les textes andins du XVII è siècle}

\section{Résumé}

Cet essai analyse la notion de pouvoir ethnique, et les figures discursives de l'identité de l'identité que I'on trouve en bonne place dans deux textes andins du XVII siècle, de grande complexité, postérieurs 
aux oeuvres de Guaman Poma de Ayala et de Garcilaso de la Vega. En reprenant les principes de la scholastique médiévale, du «droit naturel », du «bien commun» et du «bon gouvernement», ces écrits souhaitaient légitimer le droit des sujets andins à exercer le gouvernement de leurs caciquats, dans la mesure où la domination espagnole au Pérou en avait transgressé les principes de base. Par la dénonciation des abus et du racisme perpétrés contre les Indiens, ces manuscrits soulignent les contradictions inhérentes au régime colonial, en particulier l'effet perturbateur des réformes de Toledo qui aggravèrent l'esclavage des Indiens et accentuèrent le déclin des caciquats andins. En se définissant comme «noble», «chrétien » et « loyal sujet», l'auteur andin cherchait à entamer une négociation culturelle avec la Couronne en vue d'obtenir le caciquat, d'accroître son autorité ethnique et son prestige social, tout en nous offrant une remise en cause précoce des hiérarchies sociales de la Colonie.

Mots clés : auto-gouvernement andin, écriture andine, inclusion sociale andine, identité ethnique, racisme colonial

\title{
Diffuse cultural frontiers: ethnic autonomy and identity in andean texts of the XVII ${ }^{\text {th }}$ century
}

\begin{abstract}
This essay examines notions of ethnic power and discursive constructions of identity in two important Andean texts written after the age of Guaman Poma de Ayala and Garcilaso de la Vega»s works. Reworking scholastic medieval notions of «natural law», «common good», and «good government», these writings sought to legitimize the right of Andean peoples to rule their own political bodies given that Spanish rule in Peru transgressed basic notions of legitimacy. Criticizing the abuses and racism that Andeans were subject to, these manuscripts unmasked the inherent contradictions of colonialism, in particular the dislocating effect of the Toledan Reforms, which unleashed Indian slavery and the decline of Andean cacicazgos. Introducing himself as «noble», «Christian», and «loyal subject», the Andean writer attempted a cultural negotiation with the Spanish Crown to obtain a cacicazgo and carve new spaces of ethnic authority and social prestige, while advancing a reformulation of the racial hierarchies of colonialism.
\end{abstract}

Key words: Andean self-government, andean writing, andean social inclusion, ethnic identity, colonial racism

La resistencia al poderío español en los Andes con frecuencia adoptó formas más sutiles y complejas que las rebeliones o las conspiraciones. Con la consolidación de las instituciones coloniales y el consecuente deterioro de las indígenas en el siglo XVII, los sujetos andinos letrados adelantaron un movimiento político-cultural por su inclusión en las nuevas instituciones en busca de espacios políticos autónomos y en contra del racismo colonial. La disputa por el curacazgo del Repartimiento de Luringuanca en la provincia de Jauja (Perú) en la segunda mitad del siglo XVII, es parte de tal movimiento, la cual generó un prolongado pleito (1656-1671), largos viajes del litigante indígena a la Corte, y una producción substancial de escritura andina, que nos ofrece la oportunidad de estudiar aspectos clave de la cultura política indígena colonial.

Este ensayo explora la conceptualización andina de poder étnico y las construcciones discursivas de identidad que figuran prominentemente en dos textos relativos al pleito mencionado y atribuidos a Don Jerónimo Lorenzo Limaylla, indígena de la élite de la provincia de Jauja y quien firma como litigante. Su nombre aparece en la cubierta del 
«Memorial» (c. 1677) y la «Representación» (c. 1667), que fueron enviados al Rey y cuyas copias hoy reposan en la Biblioteca del Palacio Real en Madrid1. Propongo que las reformas del virrey Francisco de Toledo2 involuntariamente dieron renovado ímpetu a la crítica indígena anticolonial ya que la lucha andina por la abolición de la mita de Huancavelica y Potosí, y por los cacicazgos, se expresó significativamente a través de la escritura. En los textos arriba mencionados, el escritor cuestiona la legitimidad del dominio español y legitima el derecho al autogobierno étnico mediante la reformulación de principios propios de las teologías políticas europeas del medioevo tardío las que aplica a la situación política andina bajo el Imperio español. La agenda que subyace en su escritura es de autonomía étnica con una redefinición de la noción colonial de jerarquías sociales para reposicionar las élites andinas. El autor reformula y negocia culturalmente las identidades indígenas incorporando valores y símbolos de poder coloniales buscando representar a las élites andinas como gobernantes legítimos e inveterados.

\section{LA NATURALEZA DE LA ESCRITURA Y AUTORÍA ANDINAS}

La escritura indígena en las sociedades hispanoamericanas estaba inmersa en el proceso de transculturación que acompañó a las relaciones coloniales. La evangelización promovió diversas formas de educación y formación intelectual indígena por parte de las órdenes religiosas ya fuera a manera individual o en los colegios de caciques, seminarios, y aun en las doctrinas. La autoría indígena no puede ser vista como el acto solitario del escritor aislado de sus relaciones y conflictos sociales. Los textos andinos son ciertamente el resultado de una estrecha interacción entre curas, curacas, mestizos y aun criollos letrados simpatizantes de las causas indígenas. Todavía más importante es que los indígenas escritores mismos contribuyeron con el conocimiento acumulado de su experiencia de subordinación en el mundo colonial. Como sujetos letrados que también eran, incorporaron las teologías a las que fueron expuestos, reformulándolas para transmitir persuasivamente su visión política y así darle autoridad a sus demandas.

El historiador José Carlos de la Puente Luna ha cuestionado recientemente la identidad de Jerónimo Lorenzo Limaylla (en adelante J.L.L.) como el verdadero litigante en la larga disputa por el curacazgo de Luringuanca, lo cual equivale también a cuestionar la autoría de los dos textos en discusión. A partir de los documentos del litigio y otras fuentes anteriores al mismo, y siguiendo en líneas generales los argumentos de la parte contraria, Bernardino Mangoguala Limaylla (en adelante B.M.L.), Puente Luna propone que el verdadero litigante por el cacicazgo era en realidad un indígena tributario del pueblo de Reque (Trujillo) de nombre Lorenzo Ayun Chifo, un impostor que adoptó el nombre de J.L.L., quien supuestamente había muerto de corta edad (Puente Luna, 2006)3. Puente Luna descarta

1 Ver títulos completos de los manuscritos en la lista de obras citadas. Estos textos forman parte del abultado legajo del proceso judicial iniciado por Jerónimo Lorenzo Limaylla, situado en AGI, 1656-1671, Escribanía, 514C. Para facilitar su comprensión, la ortografía y puntuación de los textos originales han sido ajustadas al español moderno.

2 Las reformas toledanas (1569-1581) consolidaron el sistema colonial en el Perú. Impusieron la relocalización de los ayllus en pueblos de indios (reducciones) implantando nuevas formas de gobierno, la fijación de nuevas tasas de tributo y nuevos métodos para su cálculo, y la imposición de la mita obligatoria, todo lo cual desató dislocaciones de largo plazo en las sociedades andinas bajo el dominio colonial. El Primer nueva corónica y buen gobierno (1615) de Guaman Poma de Ayala fue quizás la primera respuesta de un letrado andino a las reformas de Toledo, y el antecedente más inmediato a la crítica anticolonial en los textos aquí analizados. Sobre las reformas toledanas y el impacto social de la mita ver Cole (1985: 25, 123-124), Spalding (1974). Ver las leyes toledanas relativas pertinentes en Lohmann Villena \& Saravia Viejo (1986: 1-30).

3 Limitaciones de espacio impiden aquí una exposición detallada de los importantes argumentos que sustentan esta hipótesis. Ver la discusión completa en la tesis aquí referida. 
cualquier posibilidad de que los textos en discusión hayan sido escritos por curacas, como se lee en los documentos originales ${ }^{4}$. Puente Luna propone una tesis interesante y bien documentada que debe considerarse con atención. Sin embargo, su discusión no es suficiente para cuestionar la autoría de los dos textos que me ocupan en este ensayo y sus argumentos sobre la identidad del litigante no son todavía concluyentes5 ${ }^{5}$. Si bien Puente Luna considera al «litigante», y posible autor Ayun como el típico indio «culturizado», arribista social y pasivo imitador de los modelos franciscanos de santidad (Puente Luna, 2006: 9-10), mi análisis de los memoriales al Rey referidos atrás revela una práctica intelectual de resistencia andina y el(los) sujeto(s) detrás de su autoría como verdadero(s) agente(s) intelectuales cuestionadores del colonialismo. La hipótesis de Puente Luna, sin embargo, merece atención y mayor investigación por su gran potencial para estudiar las estrategias de acceso al poder cacical por parte de indígenas del común en un mundo colonial racializado. Igualmente ofrece la posibilidad de estudiar el tema de la construcción de identidades étnicas a través del performance de poder, lo cual Puente Luna mismo ha empezado a desarrollar en su tesis.

J.L.L. al igual que su oponente B.M.L. estaban emparentados con uno de los más poderosos y antiguos linajes del valle del Mantaro en la provincia de Jauja, y estudiaron en el Colegio de Caciques del Cercado (Lima) en 1648 (Tello, 1923). Por otra parte, J.L.L. y Ayun eran andinos ladinos que habían tenido como mentores a franciscanos doctrineros de su región6. Poder establecer el tipo y grado de intervención de los franciscanos en los textos referidos es imposible, pero quizás sea más relevante anotar que la visión de quien los escribió estaba claramente atravesada por las filosofías políticas que tanto franciscanos como jesuitas enseñaban en sus colegios seminarios7. Los textos expresan

4 Jerónimo Lorenzo Limaylla ha sido hasta ahora aceptado por varios historiadores como el autor de los manuscritos al Rey (véase Pease, 1992). Basándose en los elementos biográficos de los involucrados, Alaperrine (2004) rechaza el argumento del «imposton», originalmente esgrimido por B.M.L en contra de J.L.L.

5 Por ejemplo, dos cartas de 1660 y 1961 citadas por el mismo Puente Luna (2003: 133) merecen mayor discusión. En ellas B.M.L., quien fuera reconocido en 1661 por la Audiencia de Lima y reconfirmado en 1671 por el Consejo de Indias como el legítimo heredero del cacicazgo de Luringuanca, escribe a J.L.L., su oponente, revelando elementos que cuestionan la validez de la hipótesis de la suplantación de J.L.L. En tales cartas B.M.L. deja claro que J.L.L. es su representante legal en Lima, y además de dirigirse a él como «sobrino» y «pariente» le agradece su apoyo diciendo: «al fin como dice aquel refrán que siempre la sangre tira y reconoce a los parientes». Aunque los motivos de las cartas no son claros, y las supuestas cartas de J.L.L. a B.M.L. no se conocen, se podrían cuestionar varios puntos. Primero, ipor qué B.M.L. confiaría sus asuntos legales en Lima a un supuesto «impostor» y quien fuera precisamente su oponente en el litigio? Segundo, ¿si supuestamente J.L.L. había muerto siendo niño, por qué B.M.L. le enviaba cartas más de 20 años después y lo trata con familiaridad? Tercero, ipor qué B.M.L. no argumentó en su favor durante el litigio, que en 1648 él y J.L.L. habían asistido juntos al colegio de caciques en el Cercado de Lima como lo demuestra el libro de registros del colegio? Más allá de estas cartas, sin embargo, el autor logra poner en tela de juicio importantes aspectos de la identidad del litigante. Para los fines prácticos de este ensayo y para designar el autor de los manuscritos, continuaré utilizando, sin embargo, el nombre de Jerónimo Lorenzo Limaylla tal como aparece en la portada de los documentos originales, hasta que la discusión sobre la autoría arroje resultados más concluyentes.

6 Más conocidos como «Indios ladinos» los amerindios convertidos al catolicismo y proficientes en español además de haber adquirido costumbres españolas y adoptado roles como líderes mesiánicos, litigantes, oficiales de la Iglesia y el Estado y hasta escritores, se hicieron más visibles a medida que se desarrollaba la interacción entre los mundos andino y español (Adorno, 1991: 232-272).

7 En sus colegios, los jesuitas y franciscanos enseñaban las doctrinas escolásticas del «bien común» y el «derecho natural», y particularmente los jesuitas enseñaban los principios neo-escolásticos de Francisco de Vittoria y Francisco Suárez, quienes cuestionaron la legitimidad del dominio español en América y apoyaron el tiranicidio. Las Casas fue el autor fundacional de la crítica anticolonial presente en textos como el de Guaman Poma y Limaylla. Igualmente el Thesaurus indico de Diego de Avendaño, con su condena Lascasiana a los mineros y su ataque a las tesis aristotélicas justificatorias de la esclavitud, circulaba entre los discípulos de los jesuitas en los Andes. A su vez desde el campo franciscano, los escritos fundacionales de Fray Jerónimo de Mendieta en Méjico (1526-1604) contra la esclavitud y por la igualdad de los humanos ante Dios, inspiraron a Fray Buenaventura de Salinas y Córdoba para continuar la crítica franciscana de la mita de Potosí y abogar por la causa indígena (Las Casas \& Reyes Cano, 1994; Avendaño \& Muñoz García, 2001; Mendieta et al., 1997; Salinas y Córdoba, 1957). 
la transculturación del imaginario político europeo y su utilización y reformulación por los sujetos letrados andinos para interpretar su realidad, como lo demuestra el análisis discursivo de la sección siguiente8.

Como respuesta a la intervención toledana en los Andes, los textos avanzan una crítica a la brutalidad de la mita de Huancavelica acentuada por la catástrofe demográfica indígena, lo cual incrementó el número de indios ausentes de los pueblos agravando la situación de los curacas frente al poder colonial (Cole, 1985: 25, 123-124). Desde las primeras décadas de las reformas toledanas empezó una campaña contra el servicio personal liderada por los caciques principales de la órbita de las mitas de Huancavelica y Potosí. La campaña involucró principalmente la escritura de memoriales al Rey, viajes transatlánticos de los curacas para negociar en la corte la exención del servicio personal, y en últimas la abortada rebelión de 1666 en Lima9.

\section{EL «DERECHO NATURAL» A LA AUTONOMÍA POLÍTICA ANDINA}

Cuando el furor Lascasiano de los debates iniciales del siglo XV sobre la legitimidad de la Conquista y la condena de la crueldad de encomenderos y mineros perdía vigor después de las Leyes Nuevas y el afianzamiento de la evangelización, los sujetos letrados andinos se insertaron en la discusión y continuaron su crítica por el resto del Período Colonial. En los dos textos bajo estudio, se asume que la armonía social del Imperio debería estar ligada a la justicia social para los súbditos indígenas. Apropiándose de la noción escolástica del «derecho divino», el autor se propuso demostrar la ilegitimidad del gobierno español en los Andes mientras que se vale de nociones como el «bien común» y el «derecho natural» para legitimar el derecho de los señores étnicos andinos de autogobernarse. Cuestiona la interpretación monolítica del «derecho divino» señalando que cuando Dios creó a todos los hombres (no solo a los cristianos) a su imagen y semejanza y les dio poder de gobernar sobre otras criaturas de «menos razón», Dios no hizo distinción alguna entre «creyentes» e «infieles». Por tanto todos los hombres, incluyendo los «infieles» amerindios, tenían el «derecho natural» a todo lo que emanara del poder divino (incluido el derecho a gobernar), el cual era el máximo principio legitimador. Aunque Limaylla extiende el calificativo de «infiel» a los sujetos andinos, lo hace para otorgarles el «derecho natural» a gobernar su propio pueblo. Este derecho natural era definido como:

8 La historiadora Ana María Lorandi incluye los textos de Limaylla como parte de una «matriz utópica» y como expresión del desarrollo de una «conciencia étnica basada en el retorno del Inca», de tono mesiánico a mitad del siglo XVII (Lorandi, 2005: 56) (Traducción mía). Si bien durante el siglo XVIII emergen claramente discursos mesiánicos en las rebeliones andinas, la argumentación político-filosófica en los manuscritos en discusión no parece evidenciar tal «matriz utópica». El intento de Limaylla por validar su nobleza según su linaje incaico y local parece responder más a la tradición española que a la incaica. La escritura de Limaylla ofrece fundamentalmente una defensa política y teológica del derecho al autogobierno andino a través de la reformulación de elementos escolásticos.

9 Entre la escritura de crítica colonial producida durante esta coyuntura social se encuentra el «Memorial de Charcas» compuesto por 24 caciques principales liderados por Don Fernando de Ayavire del pueblo de Socaca (provincia de Charcas), el cual puntualiza los cambios introducidos por Toledo y su impacto en Charcas. Posteriormente y desde 1646, cerca de 15 caciques de las regiones involucradas en la mita de Huancavelica compusieron memoriales cuestionando la violencia del sistema y viajaron personalmente a España a presionar por la exención de la mita y denunciar la inefectividadad de las políticas reales (cédulas de 1601 y 1609 prohibiendo el servicio personal). Entre ellos se encontraban Don Carlos Collatopa, Don Carlos Chimo, Don Melchor Inga, y el sacerdote Fray Juan Madre de Dios (AGI, 1646, Lima, 15: s/n; 1660, Lima, 17: s/n). En 1646, el andino nombrado como Don Lorenzo Ayllón (o Ayun, según Puente Luna) denunciaba los vejámenes cometidos en la minas de Huancavelica, pidiendo al Rey que «los indios de dicha mina sean relevados por término de 30 o 20 años para que descansen y retornen a las reducciones los que han huido y se puedan adoctrinar en la fe católica» (AGl, 1646, Lima, 15: s/n). 
«[U]n regalo divino a todos los hombres, no solo a los fieles sino también los infieles, porque el divino creador no distinguió entre ellos. Así, no es lícito quitar este derecho a ninguno contra su voluntad después de constituido señor y dueño suyo, aunque sea infiel... Porque ninguno puede, aunque tenga poder y autoridad política, hacer injusticia ni quebrantar el derecho natural y divino porque incurriría en el delito y pecado opuesto a la virtud de la justicia» (Limaylla, [c. 1677]: 214v) (Énfasis mío).

En otras palabras, el subyugamiento de los indígenas por los españoles que tomaron sus tierras en la Conquista constituyó una doble trasgresión a la ley divina: fue un crimen contra los hombres y un pecado contra la voluntad divina. Así Limaylla invalida el derecho español al dominio político en los Andes y extiende el principio del derecho natural al autogobierno y la conservación de sus recursos a la «república de indios»:

«Todas las [n]aciones..., aunque sean de Infieles, que poseen tierras y reinos los cuales poseían desde su principio... y los cultivaron, son libres porque no reconocieron superior sino a aquellos a quienes dieron la obediencia, pagaron vasallaje y rindieron tributo. Y estos tienen derecho a su libertad, y sus [r] eyes y [p]ríncipes tienen sobre ellos la potestad que ellos les dieron... también sus [p]ríncipes y [s]eñores son libres en gobernarlos, guardando a los vasallos la inmunidad preciosa de su libertad, para que así el dominio que tienen sobre sus bienes le conserven» (Limaylla, [c. 1677]: $219 v-20)$.

Limaylla usa la categoría política escolástica de «bien común» para sustentar el derecho andino a la autonomía política. Solo un gobernante que luche por el bien común podrá garantizar que a través de las leyes triunfe el «bien común» sobre los intereses individuales. Se entiende aquí el «bien común» como la obligación del gobernante de preservar y garantizar «buena educación y gobierno de los individuos que constituyen la República» (Limaylla, [c. 1677]: 215v). El escritor defiende la autonomía étnica proponiendo una negociación político-cultural en la que la conversión sería permanente si los señores étnicos permaneciesen en el poder de los cacicazgos:

«Los reyes de España deben preservar sus señores naturales y hacienda [de los indios], para que así la fe y la religión Cristiana no se haga odiosa e intolerable, ... con riesgo de sus almas y culpa manifiesta de quien hace penosa la ley que se fundó en amor y caridad. Por esta razón les incumbe a los reyes su defensa para librarlos de tantas extorsiones... y para que desconfiados del remedio no huyan el rigor, por parecerles menos daño el volver a la idolatría y dar adoración a dioses falsos..., desesperados, malogrando el fin de la predicación evangélica» (Limaylla, [c. 1677]: 224-24v) (Énfasis mío).

La amenaza del retorno a la idolatría es una estrategia retórica recurrente de los intelectuales andinos. En el trasfondo se escucha la crítica a la Iglesia y a la tiranía de los mineros de Huancavelica quienes obstaculizaban el bien común andino. Los neo-escolásticos españoles como el jesuita De Vittoria abogaban por el derrocamiento del gobernante cuando éste devenía en tirano (Reijo, 1963: 80-85). Aunque tal llamado no es explícito en los textos de Limaylla, estos forman parte de las campañas contra la mita y se cree que otros de sus escritos ayudaron a la frustrada rebelión de 1666 liderada por Manco Capac en Lima contra la mita y el tributo. Según Pease, Limaylla mantenía correspondencia con Bartolomé Mendoza, autoridad indígena acusada de instigar la rebelión, a quien se le confiscaron en 1666 cartas firmadas por Limaylla fechadas en 1656 (Pease, 1992: 165). 


\section{LA LUCHA POR LA INCLUSIÓN SOCIAL Y LA FORMULACIÓN DE IDENTIDADES ÉTNICAS}

Desde las postrimerías de la Conquista y durante todo el Período Colonial, las autoridades indígenas y sus representantes viajaron a la Corte Real a pedir justicia y movilidad social. Reclamaban varias formas de mercedes (recompensas por «buenos servicios» al Rey) desde escudos de armas, membresía en órdenes caballerescas, derecho a portar armas y servir en la milicia, hasta nombramientos en el servicio civil y eclesiástico, ingreso al sacerdocio, y acceso a establecimientos de educación. Estos aparecían como los nuevos símbolos de honor y nobleza adheridos al reconocimiento de autoridad política dentro de las convenciones culturales coloniales10. Para los sujetos andinos tales símbolos y espacios parecían ofrecer la posibilidad de mayor autonomía étnica si se lograban extender a la «república de indios».

De acuerdo al formalismo de las probanzas de mérito españolas, los peticionarios indígenas del siglo XVII también listaban sus múltiples servicios al Rey. Alegaban haber apoyado la conquista española, la recolección del tributo, la empresa misionera y hasta haber contribuido a la extirpación de idolatrías; de conformidad con los estándares ibéricos de «pureza de sangre», se presentaban como los verdaderos descendientes de los incas, validación generalmente aceptada por la Corona. Cerca de 1677, J.L.L. proclamaba ser cacique principal y descendiente directo de «Pachacuti inca, noveno rey, nieto de Viracocha, octavo Inca, y rebisnieto de Yaguarhuacas, séptimo Inca...» y además dejaba constancia de su descendencia de los antiguos señores étnicos de la provincia de Jauja (Limaylla, [c. 1667]: 211)11.

Concientes de su posición subordinada en una sociedad jerarquizada por la raza, las élites andinas emprendieron una lucha por participar en el estrecho margen de oportunidad social posible para disfrutar de la libertad, respeto y reconocimiento político que la nobleza colonial tenía. En su lucha por el cacicazgo de Luringuanca, Limaylla no solamente viajó varias veces a la corte a avanzar su disputa legal, sino que intentó su legitimación política insertándose en las organizaciones de prestigio creadas para los nobles españoles. Una de sus estrategias discursivas fue la reformulación de la noción colonial de jerarquía racial, «naturalizando» el derecho a privilegios para las élites, incluyendo las élites andinas. El escritor propone la igualdad entre los indios nobles y los nobles españoles, como vasallos que ambas élites eran del mismo Rey. Como reafirmación, Limaylla ejecuta una reversión retórica de los roles sociales de ambos grupos nivelándolos a partir de degradar a los españoles a la condición de mitayos y tributarios y elevar a los indígenas de élite. Así, el escritor suplica al monarca que:

«[S]e dignase instituir para los indios nobles, en quienes concurriesen las calidades expresadas en él [memorial], una [c]aballería, u [o]rden a semejanza de las [m]ilitares... cognominada y patrocinada con el título de Santa Rosa, por ser la protosanta de aquellas partes, dándoles la insignia como la del hábito de Santiago...y que se les envista con las ceremonias que más fueren del agrado de S. M.... Y que esta merced se les haga a aquellos [i]ndios principales, [n]obles, [c]aciques, [g]obernadores y [c]uracas... ordenando que primero preceda información de su ascendencia y nobleza, y que hayan hecho algunos servicios particulares en la manera que hayan podido según las partes donde habitaren» (Limaylla, [c. 1677]: 204, 208v).

10 Para una reconstrucción histórica de la búqueda de privilegios por parte de la nobleza incaica bajo el domino español, ver Lorandi, 2005: 38-60.

11 De manera similar en 1646, el andino Don Lorenzo Ayllón se reclamaba descendiente de los señores étnicos del Repartimiento de Luringuanca (AGl, 1646, Lima, 15: s/n). 
«... Y siendo señor estos [indios] tan libres como los españoles, es conveniente obligar al trabajo tanto a los unos como a los otros y no solo deben [los españoles] ayudarlos al servicio personal... sino [que], como los indios, pagasen tributo a V. M.» (Limaylla, [c. 1667]: 236).

Una orden de caballeros para indios nobles no era simplemente un asunto de arribismo social. Era una estrategia política para ganar legitimidad de acuerdo a los estándares europeos buscando aproximarse un poco más al curacazgo por el cual luchó, y quizás desde allí mejorar la situación social de los indígenas en Huancavelica. El asunto de la identidad étnica noble según convenciones coloniales es, sin embargo, más complejo ya que nobleza y autonomía étnica aparecen aquí subrepticiamente interrelacionadas. Limaylla no pedía membresía en una orden de caballeros españoles, sino que esperaba la creación de una orden propia para indios nobles. Su intención era claramente permanecer en un espacio de poder autónomo y separado de los españoles y a la vez ganar su respeto. El carácter propiamente indígena se expresa en que la orden estaría bajo el auspicio de Santa Rosa12. Pero la identidad andina así expresada estaba matizada por la ambigüedad, ya que la orden debería tener la insignia católica del hábito de Santiago, lo cual expresa su intento de reconciliar su ancestro andino con el de los españoles blancos.

Explorando a fondo subyace en los textos una negociación cultural en la que las autoridades indígenas cooperarían en la continuación de la conquista española y las campañas de conversión religiosa a cambio de mantener los señoríos étnicos, lo cual añade nuevos matices a la cultura política andina de la época:

«Que a todos aquellos Indios nobles que atrajeran o redujeran a aquellos Indios infieles a nuestra [s]anta [f]e [c]atólica y a la obediencia de V. M., no solo fuese servido de mandar quedasen por caciques de ellos, sino que también se les hiciese merced de la dicha insignia [orden de Santa Rosa] con el mismo reconocimiento y obligación arriba dicha» (Limaylla, [c. 1677]: 209) (Énfasis mío).

Es interesante, sin embargo, que al tiempo que reclama los señoríos étnicos para los amerindios nobles, Limaylla acepta convenciones coloniales como el vasallaje andino al Rey, la necesidad de la evangelización y las distinciones raciales españolas («pureza de sangre»). La complejidad de su construcción es más prominente si se tiene en cuenta que una porción substancial de la «Representación» se dedica a cuestionar el abuso de los españoles, denunciar la degradación moral indígena y el flagrante incumplimiento del Rey de sus deberes de reciprocidad con sus súbditos andinos ${ }^{13}$.

Aunque Limaylla intenta, hasta el borde del cansancio, mantener una posición consistente como sujeto leal y cristiano, su construcción discursiva de identidad es problemática. Lucha por sumarse a las voces que proclamaban la efectividad y conveniencia de la evangelización, pero no puede ocultar que más de una centuria y media después de la conquista española los amerindios aún resistían el proyecto civilizador de la Iglesia Católica Romana, y que la idolatría andina era todavía una amenaza latente con la que los misioneros tendrían que

12 Entre los devotos de Santa Rosa, los indígenas se contaban por miles en el Perú; aparentemente su nombre se asociaba con profecías sobre el retorno del Inca. Santa Rosa era además la patrona de varios pueblos andinos Según Millones algunos veían en ella el aspecto femenino del gobierno Inca, equivalente a la coya, mientras que Atahualpa era su correspondiente masculino (Millones, 1988: 44-49).

13 La mayor parte de la crítica se centraba en la opresión del trabajo en las minas, la condena a los obrajes forzados y la presión creciente del tributo a medida que el colapso demográfico indígena avanzaba: «Este ejercicio es tan penoso que excede al trabajo de estar en galeras... Y lo mismo que padecen en las minas los pobres Indios, aún con mayor rigor y crueldad son tratados en los obrajes, prisión violenta, donde forzados trabajan sin jornal competente, llevando el provecho los dueños del obraje... Y así, Señor es necesario atajar el daño prohibiendo los obrajes» (Limaylla, [c. 1667]: 237-242). 
lidiar aún por algún tiempo ${ }^{14}$. Aunque en su prosa el autor andino intenta con desespero abrazar el catolicismo, intentando a veces distanciarse a sí mismo y a su pueblo de su pasado «idólatra», no puede dejar de admirar el logro de la administración incaica en el cuidado material y espiritual de sus miembros (Limaylla, [c. 1677]: 208). A la vez que insiste con ansiedad en su identidad católica y su voluntad de cooperación con los objetivos del plan colonial, Limaylla critica visceralmente el incumplimiento de las leyes a favor de los indios y el cristianismo de los españoles.

\section{CONCLUSIÓN}

Una de las características de la construcción intelectual andina producto de la transculturación propia del mundo colonial fue la incorporación y replanteamiento de elementos políticoteológicos aceptados en el medioevo tardío en Europa y en la temprana era moderna en España, usándolos como técnicas intelectuales para resistir la exclusión colonial. En los manuscritos en cuestión, Limaylla utilizó tales dispositivos retóricos para sustentar la legitimidad del señorío andino sobre sus cacicazgos y deslegitimar el domino español en los Andes.

Con su elaboración, el escritor andino contribuyó a desvelar la inconsistencia de las reformas toledanas, que desataron la esclavitud indígena y el declinar de los cacicazgos andinos, a la luz de principios escolásticos como el «derecho natural», la «ley divina», el «bien común» y el «buen gobierno». Tales principios que una vez legitimaran las monarquías europeas, al ser trasladados a la situación colonial de los indígenas del Perú se tornan en factores desestabilizadores del discurso colonial y la legitimidad española en América, revelando la injusticia social como el carácter inherente que el colonialismo español adquirió para los súbditos andinos. Tales interpretaciones de las categorías medievales tomistas, en últimas, condujeron al autor a reclamar que se cumpliera el pacto de reciprocidad violado por los colonizadores y el mismo Rey, al no hacer cumplir las leyes a favor de los indios:

«Yo no pido sino que se ejecute lo que V. M. manda» (Limaylla, [c. 1677]: 236v-37).

Si bien el Rey negó la petición de crear una orden de indios nobles, la lucha por abrir espacios para ellos en instituciones coloniales fue, en últimas, un intento andino por combatir el racismo colonial:

«Así [los españoles] se detendrán de despreciarlos y les causará respeto y estimación» (Limaylla, [c. 1677]: 209v).

Presentándose a sí mismo como «noble», «cristiano», y «sujeto leal», el intelectual andino intentaba una negociación cultural para la obtención del cacicazgo y la creación de espacios de autoridad étnica y prestigio social. El lenguaje utilizado, sin embargo, delata la ambigüedad que habita sus esfuerzos por identificarse con el proyecto colonizador, y hace problemática la coexistencia retórica entre la resistencia político-cultural de la autonomía étnica y la lealtad colonial. Finalmente, la subversión del propósito de la teología política y la alteración del orden jerárquico racial operados en estos textos, desafía el papel jugado por la alfabetización, la educación religiosa y la evangelización de los indígenas como instrumentos de control social. Si bien tales instrumentos adentraron a los amerindios en el mundo español de las letras y la cristiandad, ellos también actuaron como agentes intelectuales capaces de transformar tales instrumentos y combatir con ellos el aplastamiento de las sociedades andinas en la era de las reformas toledanas.

${ }^{14}$ En los siglos XVII y XVIII, aún se oficiaban rituales religiosos andinos, a veces incluso conducidos por indios ladinos miembros de las parroquias y el gobierno locales (Spalding, 1985: 169, 171). 


\title{
Referencias citadas
}

\section{Fuentes primarias}

\section{Archivo General de Indias (AGI)}

\author{
$1646 \quad$ Lima, 15: s/n \\ $1660 \quad$ Lima, 17: s/n \\ 1656-1671 Escribanía, 514C
}

\section{Biblioteca Real del Palacio (BRP)}

c. 1667 Jerónimo Lorenzo Limaylla, «Representación hecha al Señor Rey Don Carlos II. Por Don Jerónimo Lorenzo Limaylla, indio cacique del Repartimiento de Luringuanca de la Provincia de Jauja, Reino del Perú, como poder teniente de los demás caciques gobernadores de las demás provincias del dicho reino y como parte principal y legítima, a quien toca mirar por el alivio y conservación de los Indios. La cual consiste y estriba [en] la mayor propagación de la fe y aumento de la real hacienda, a fin de que S. M. se dignase dar las providencias convenientes para su buen tratamiento, y que no fuesen vejados ni oprimidos en la dura servidumbre de los españoles» (Sign. II/2848: ff. 211-247v)

c. 1677 Jerónimo Lorenzo Limaylla, «Memorial Dado à la Majestad del Señor Don Carlos II por Don Jerónimo Lorenzo Limaylla, indio cacique principal y gobernador de la Provincia del Valle de Jauja del Repartimiento de Luringuanca en el Reino del Perú, suplicando que S. M. [su majestad] se dignase instituir para los Indios nobles, en quienes concurriesen las calidades expresadas en él, una caballería u orden a semejanza de las militares, con que se obviarían los graves inconvenientes que en el día se experimentaban. Y sería de alivio, honor y reconocimiento para aquellas naciones y de grande utilidad al real erario por las razones que en él se refieren» (Sign. 2848: ff. 204-210v)

\section{Fuentes secundarias}

ADORNO, R., 1991 - Nosotros somos los kurakakuna. Imágenes de Indios Ladinos. In: Transatlantic Encounters (K. J. Andrien \& R. Adorno, eds): 232-272; Berkeley: University of California Press.

ALAPERRINE, M., 2004 - Enseignements et enjeux d'un héritage cacical. Le long plaidoyer de Jerónimo Limaylla, Jauja, 1667-1678. In: Les autorités indigènes entre deux mondes. Solidarité ethnique et compromission coloniale (B. Lavallé, ed.): 103-129; París: Publications de la Sorbonne-Nouvelle, Université de Paris III.

AVENDAÑ̃, D. de, \& MUÑOZ, A., 2001 - Thesaurus Indicum, 211 p.; Pamplona: Ediciones Universidad de Navarra.

COLE, J., 1985 - The Potosí Mita, 1573-1700. Compulsory Indian Labor in the Andes, 206 p.; Stanford, California: Stanford University Press.

GUAMAN POMA DE AYALA, F., 1980 [c. 1615] - El Primer Nueva Corónica y Buen Cobierno (J. V. Murra \& R. Adorno, eds.), 1173 p.; México, Madrid, Buenos Aires: Siglo XXI editores. 
LAS CASAS, B. \& REYES CANO, 1994 - Brevísima Relación de la Destrucción de las Indias, 170 p.; Barcelona, España: Planeta.

LOHMANN, G. \& SARAVIA, M. J., 1986 - Francisco de Toledo. Disposiciones gubernativas para el Virreinato del Perú, 1569-1574, 2 tomos; Sevilla: Escuela de Estudios Hispanoamericanos, Consejo Superior de Investigaciones Científicas, Monte de Piedad, Caja de Ahorros.

LORANDI, A. M., 2005 - Spanish King of the Incas. The Epic Life of Pedro Bohorques, 258 p.; Pittsburgh: University of Pittsburgh Press.

MENDIETA, G. de, GARCÍA, J. \& GARCÍA, E. R., 1997 - Historia eclesiástica indiana, 300 p.; Mexico, D.F.: Consejo Nacional para la Cultura y las Artes.

MILLONES, L., 1988 - El Inca por la coya. Historia de un drama popular en los Andes peruanos, 106 p.; Lima: Fundación Frederick Evert.

PEASE, F., 1992 - Kuracas, reciprocidad y riqueza, 208 p.; Lima: Pontificia Universidad Católica del Perú.

PUENTE LUNA, J. C. de la, 2006 - What's in a name? An Indian Trickster Travels the Spanish Colonial World. Tesis de Maestría; Texas Christian University.

REIJO, W., 1963 - The Social and Political Theory of Francisco Suárez, 120 p.; Helsinki: Societas Philosophica Fennica.

SALINAS Y CÓRDOBA, B. de, 1957 - Memorial de las historias del Nuevo Mundo Pirú, 358 p.; Lima: Universidad Mayor de San Marcos.

SPALDING, K., 1974 - De indio a campesino, cambios en la estructura social del Perú colonial, 202 p.; Lima: Instituto de Estudios Peruanos.

SPALDING, K., 1985 - Social Climbers: Changing Patterns of Mobility among the Indians of Colonial Peru. In: Readings in Latin American History. Vol. I. The Formative Series (P. J. Bakewell, J. Johnson, \& M. D. Dodge, eds): 160-175; Durham: Duke University Press.

TELLO, J. C. (ed.), 1923 - Colegio de Caciques. Inca, 1 (4): 779-883; Lima. 